\title{
The Accuracy of Small Area Sampling of Wireless Telephone Numbers
}

\author{
Martin Barron, Felicia LeClere', Robert Montgomery', Staci Greby², Erin D. Kennedy ${ }^{2}$ \\ ${ }^{1}$ NORC at the University of Chicago, ${ }^{2}$ Centers for Disease Control and Prevention \\ Keywords: telephone surveys, geography, cell phone \\ https://doi.org/10.29115/SP-2015-0005
}

Survey Practice

Vol. 8, Issue 1, 2015

\begin{abstract}
The value of telephone surveys for assessing effects at geographic areas is impacted by increasing wireless telephone use. Highly accurate landline samples may be drawn for national, state, county, or even smaller areas; however, wireless samples have less geographic precision. This requires additional data collection effort and screening costs in order to ensure the appropriate geographic area is surveyed. In this paper, we examine the accuracy of wireless sample frame from the 2010-2011 National Flu Surveys. We illustrate differences and variations in wireless sampling accuracy for different geographic areas, focusing on variability by area in placement of wire centers related to residences. Our results suggest that the accuracy of wireless sampling may be dependent on differences in geographic areas with the accuracy of wireless sampling decreasing as the level of geographic aggregation gets more specific; landline accuracy remains relatively stable regardless of geographic specificity. To explain this phenomenon, we examine patterns of geographic dispersion of wireless telephone numbers related to telephone switch centers and geographic area. Based on the evidence from these surveys we present several options to estimate the geographic specificity of an area prior to sampling.
\end{abstract}

\section{Introduction}

Many surveys require estimates at the national, state, county, or local areas. To calculate these estimates, telephone surveys require a match of telephone numbers to the geographic area. But differences in how geography is assigned to landline and wireless telephone numbers can lead to very different levels of accuracy.

Landline and wireless sampling frames are, in principal, constructed in a similar manner. Switch centers are part of the telephone system's infrastructure to efficiently route calls from sender to receiver. Each telephone number is assigned to one switch center based on geographic location; the switch center remains assigned to the telephone number. Since the geographic location of each switch center is known, survey researchers assign an approximate geographic location to telephone numbers associated with each switch center. However, landline numbers are assigned to a particular location that rarely changes and may be assigned to the switch center closest to the location of the home. The switch center location serves as a relatively accurate proxy for landline telephone location (Marketing Systems Group 2012). Wireless numbers are mobile and assigned to the switch nearest the store where they are purchased, which is not necessarily near the respondent's home (Marketing Systems Group 2012). This makes assigning a location to a wireless telephone 
less accurate than assigning a location to a landline. Additionally, there is variability by area in placement of wire centers vs. residences, which may affect also the accurate assignment of a location.

There is limited research on the consequences of including wireless phones in the construction of geographically specific sampling frames for random digit dialing (RDD) surveys (Christian, Dimock, and Keeter 2009; Dutwin et al. 2011; Skalland, Khare, and Furlow 2012). The challenge of sampling small geographic areas for dual-frame RDD surveys (that is, surveys that randomly select sample from two sampling frames, in this case landline telephone numbers and wireless telephone numbers) using switch center assignment has not been addressed. We describe the consequences of using switch centers to make geographic assignment of wireless and landline sample lines in small areas on the 2010-2011 National Flu Surveys (NFS). We examined the proportion of telephone numbers sampled that actually belonged in the targeted geographic areas, showing the differences in the geographic accuracy between wireless and landline samples and of samples drawn at numerous levels of aggregation. We show how variation in state level switch assignment affected sub-state accuracy of assignment of sample lines to specific geographic areas.

\section{Methods}

This research uses data from the NFS sponsored by the Centers for Disease Control and Prevention. The NFS was a large (73,203 completed interviews) RDD survey targeting households with landline and wireless telephone service. Data were collected between November 1-14, 2010, and March 3-30, 2011, to provide in-season estimates of influenza vaccination coverage and influenza knowledge, attitudes, and behaviors for national and 20 selected local areas. The local areas were county clusters, individual counties, or sub-county areas (Appendix A). The data from both surveys were combined in this analysis.

Separate sampling frames were constructed by dividing the universe of telephone banks into mutually exclusive banks of landline and wireless numbers. A sample was drawn from each of the 20 local areas with the goal of completing 280 wireless and 1,120 landline interviews in each area. A $21^{\text {st }}$ sampling area consisted of all U.S. areas other than the 20 local areas which, when combined and properly weighted with the local areas, allowed calculation of national vaccination coverage estimates.

All wireless sample lines were screened for the wireless-only/mainly status of the household. Wireless only households were households where the respondent reported that he or she only had wireless service. Wireless-mainly households were households where the respondent reported the presence of both wireless and landline service, and it was unlikely that anyone in the household would pick up the landline if it rang. Wireless-only/wireless mainly households remained in the final sample. All other wireless households where respondents reported that someone was likely to pick up the landline if it rang were screened out of the final sample. 
Table 1 Summary geographic accuracy rates, National Flu Survey, selected local areas, 2010-2011 influenza season. ${ }^{a}$

\begin{tabular}{lll}
\hline Accuracy rate $^{\mathrm{b}}$ & Wireless-only/mainly & Landline \\
Census region & $93.4 \%$ & $99.8 \%$ \\
Census division & $91.1 \%$ & $99.7 \%$ \\
Bordering state & $91.1 \%$ & $99.7 \%$ \\
State & $85.9 \%$ & $99.5 \%$ \\
In-state, bordering county & $65.8 \%$ & $99.3 \%$ \\
County/county group & $42.4 \%$ & $96.0 \%$ \\
Original sampled estimation area & $40.5 \%$ & $95.5 \%$ \\
Sub-county (where appropriate) & $36.5 \%$ & $95.2 \%$ \\
\hline
\end{tabular}

${ }^{a}$ All geographic differences were significantly different between cell and landline samples $(\mathrm{x} 2>2,738.3, \mathrm{DF}=1, p<0.001)$.

${ }^{b} \mathrm{DC}$ was included in all calculations.

All respondents were asked their residential mailing address zip code. This was compared with the location of the switch center to calculate a geographic accuracy rate. We defined the geographic accuracy rate as the proportion of all respondents with a self-reported residential zip code that is within the original specified sampling area as determined by the switch location. This was used as a measure of the proportion of the sampled and interviewed households that were actually located in the geographic areas used for estimating survey statistics. For the purposes of determining geographic accuracy, we excluded the cases sampled in the sampling area outside the 20 local areas, as those cases were not selected in a way to make geographic comparisons meaningful. We recalculated the geographic accuracy rate at different levels (Table 1) of geographic aggregation for our analysis below. That is, we calculate the accuracy of a given piece of sample assuming a broader geography than originally specified. For example, we may have sampled a case at the county level, but we can ask how accurate our sampling would have been had we sampled at the state level. In order to attempt to explain the geographic patterns seen in the wireless phone results, we mapped the movement of respondents from county to county based on sampled and self-reported zip code data. Maps were reviewed for discernable patterns.

In the 2010-2011 NFS, 20,071 wireless cases completed the interview, of which 18,470 provided their residential mailing address zip code. A further 53,132 landline cases completed the interview, of which 49,830 provided their residential mailing address zip code. The American Association for Public Opinion Research (AAPOR) Response Rate $3^{1}$ (RR3) for the landline sample was 34.8 percent (November) and 35.5 percent (March). The AAPOR RR3 for wireless sample was 19.2 percent (November) and 19.3 percent (March). 
For both the landline and wireless-only/mainly samples, our analyses used cases where a respondent reported residential zip code was available. Appendix A gives the number of cases for each of the local geographic areas.

\section{Results}

Overall, 95.5 percent of the landlines sampled and 40.5 percent of the wirelessonly/mainly households sampled were located within the sampled estimation area. Table 1 presents accuracy rates at different levels of geographic aggregation (including the original sampled area, which contains different levels of geographic precision) for wireless-only/mainly and landlines samples.

The accuracy of sample location decreased as geographic areas were more finely defined (Table 1). The decline was greater among the wireless-only/mainly population where 93.4 percent of the wireless-only/mainly cases were in their sampled Census Region but only 36.5 percent were in the sub-county area where they were sampled. In contrast, 99.8 percent of the landline cases were in the sampled Census Region and 95.2 percent were in the sub-county where they were sampled.

There was variation in the accuracy rates between the selected local areas as well (Table 2). The geographic accuracy rate ranged from 9.5 percent in New Hampshire to 75.7 percent in Minnesota. With the exception of the District of Columbia, all areas had at least 75 percent of their sample located within the sample state (77.1 percent to 85.7 percent with an average of 87.57 percent).

Several patterns in the geographic distribution of sampled cases surrounding the sampling targets using the distribution of the switch centers were identified. We illustrate using data from four areas: Tennessee, Maine, New Hampshire, and Cook County, IL.

In Tennessee (Figure 1) cases not located in the sampled area were clustered in bordering counties or nearby, with the largest concentration of the out of area cases in three nearby counties (red counties). Tennessee contained a number of switches within the county of interest, but none in the surrounding counties. Individuals with wireless service in an adjoining county had a higher probability of being assigned to a switch in Davidson County. (Similar patterns were seen in New Mexico and Texas.)

In Maine (Figure 2), cases showed little geographic clustering, and cases out of the sampled area were found throughout the state. All the switches in Maine were clustered around Cumberland County; thus, there was a wide distribution of cases sampled for Cumberland actually located in other counties. (Similar patterns were seen around Philadelphia.) 
Table 2 Geographic accuracy of the wireless-only/mainly cases by local area, National Flu Survey, 2010-2011 influenza season.

\begin{tabular}{|c|c|c|c|c|c|}
\hline \multirow[t]{2}{*}{ Area name } & \multirow[t]{2}{*}{ In area matched } & \multicolumn{3}{|c|}{ Out of area } & \multirow[t]{2}{*}{ Total counts } \\
\hline & & In-state & In bordering state & In other state & \\
\hline Minnesota & $75.70 \%$ & $12.50 \%$ & $3.30 \%$ & $8.50 \%$ & 543 \\
\hline New York & $74.50 \%$ & $8.60 \%$ & $9.30 \%$ & $7.60 \%$ & 419 \\
\hline New Mexico & $69.40 \%$ & $20.00 \%$ & $4.70 \%$ & $5.80 \%$ & 569 \\
\hline AZ-Maricopa County & $65.30 \%$ & $23.30 \%$ & $4.10 \%$ & $7.30 \%$ & 763 \\
\hline CA-Los Angeles County & $62.50 \%$ & $29.10 \%$ & $0.80 \%$ & $7.50 \%$ & 491 \\
\hline TX-Bexar County & $59.60 \%$ & $33.70 \%$ & $1.20 \%$ & $5.50 \%$ & 688 \\
\hline WA-King County & $53.70 \%$ & $36.10 \%$ & $1.70 \%$ & $8.50 \%$ & 762 \\
\hline Arkansas & $52.10 \%$ & $40.70 \%$ & $5.00 \%$ & $2.20 \%$ & 1,070 \\
\hline Colorado & $50.60 \%$ & $38.90 \%$ & $2.90 \%$ & $7.60 \%$ & 864 \\
\hline CA-Fresno County & $48.30 \%$ & $47.40 \%$ & $0.60 \%$ & $3.80 \%$ & 661 \\
\hline Connecticut & $46.10 \%$ & $33.90 \%$ & $8.50 \%$ & $11.50 \%$ & 566 \\
\hline MI-Washtenaw County & $43.90 \%$ & $34.50 \%$ & $2.30 \%$ & $19.20 \%$ & 990 \\
\hline IL-City of Chicago & $36.60 \%$ & $51.60 \%$ & $2.90 \%$ & $8.90 \%$ & 907 \\
\hline TX-City of Houston & $36.50 \%$ & $56.70 \%$ & $1.10 \%$ & $5.60 \%$ & 887 \\
\hline PA-Philadelphia County & $36.30 \%$ & $44.20 \%$ & $12.20 \%$ & $7.40 \%$ & 720 \\
\hline TN-Davidson County & $33.30 \%$ & $57.10 \%$ & $4.80 \%$ & $4.80 \%$ & 1437 \\
\hline District of Columbia & $31.60 \%$ & N/A & $55.60 \%$ & $12.80 \%$ & 915 \\
\hline Georgia & $26.40 \%$ & $64.00 \%$ & $3.00 \%$ & $6.60 \%$ & 1,258 \\
\hline ME-Cumberland County & $25.30 \%$ & $58.40 \%$ & $1.10 \%$ & $15.30 \%$ & 1,328 \\
\hline New Hampshire & $9.50 \%$ & $67.60 \%$ & $10.20 \%$ & $12.70 \%$ & 2,218 \\
\hline
\end{tabular}

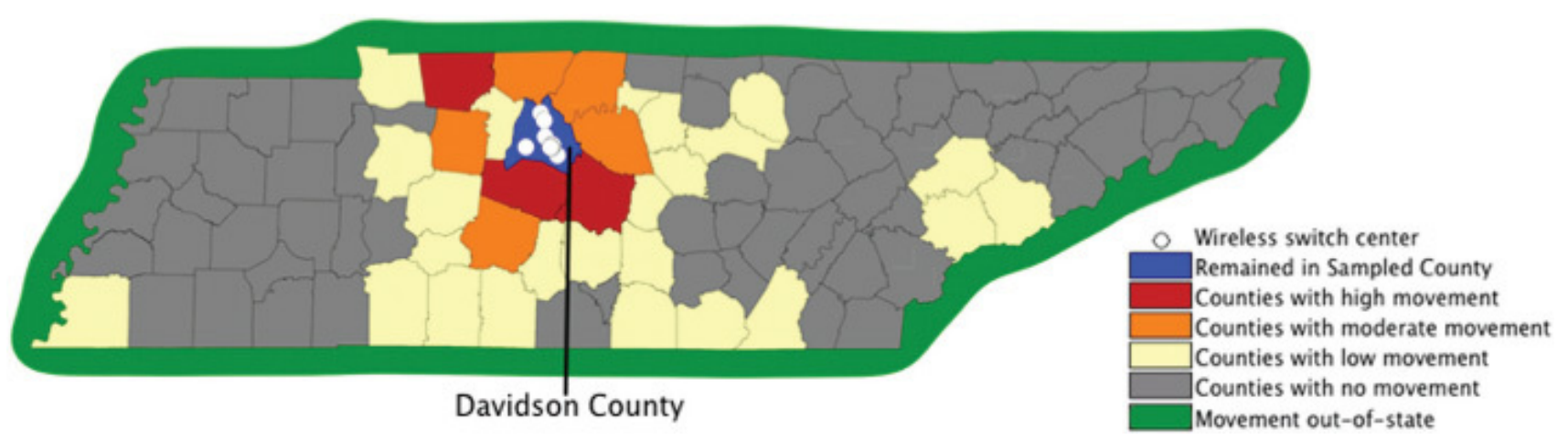

Figure 1 The location of sampled cases in Tennessee.

New Hampshire (Figure 3) was a unique example. Three Northern counties were sampled (Belknap, Coos, and Grafton), but there were no switch centers located in these counties. To sample these areas, wireless numbers were drawn from switches anywhere in the state. This led to a lower accuracy rate (9.5 percent). 


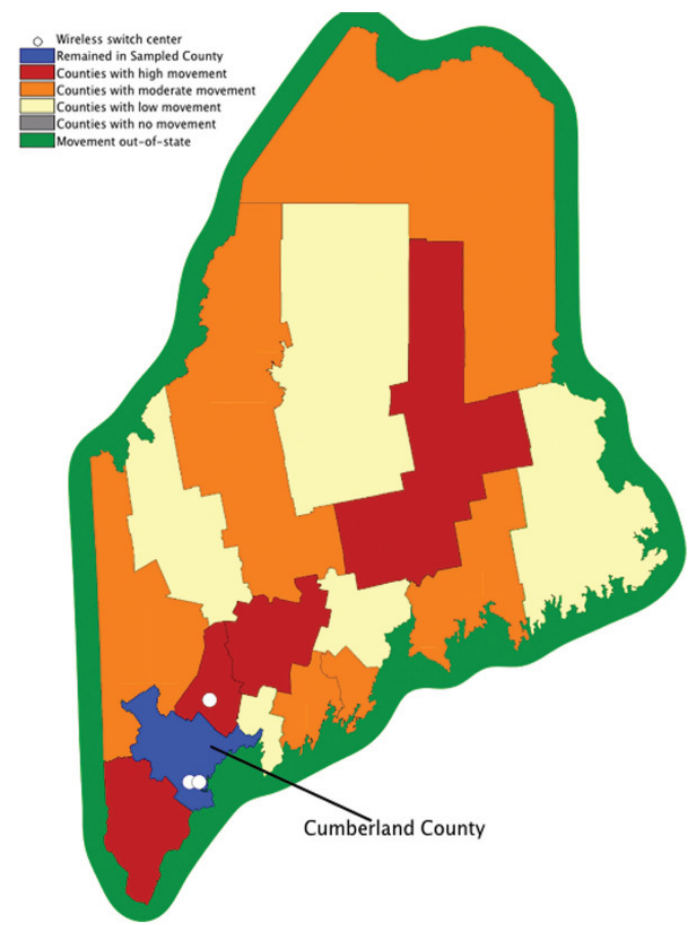

Figure 2 The location of sampled cases in Maine.

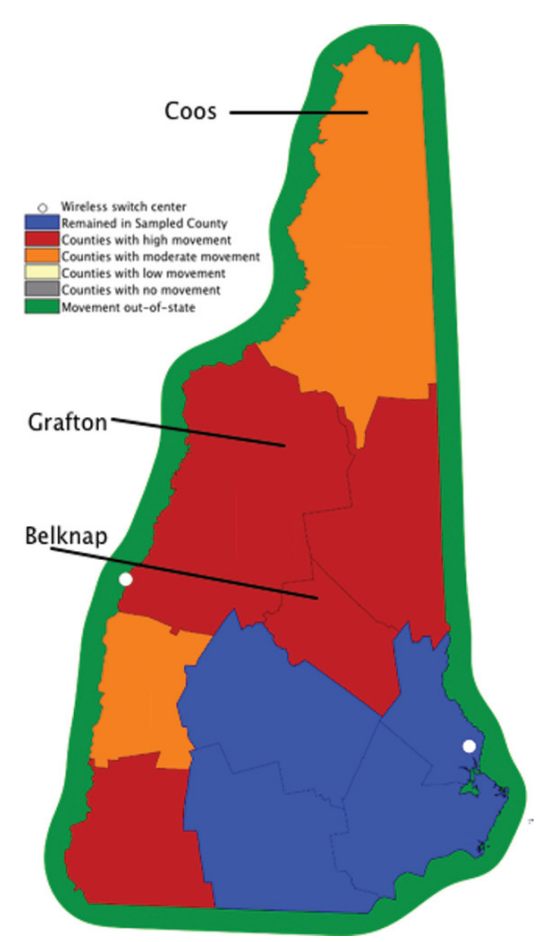

Figure 3 The location of sampled cases and switches around New Hampshire.

Sub-county sampling units also posed problems for drawing accurate samples. Though switches exist in Cook County, IL, there were few switches located in the City of Chicago (Figure 4), the sampling target for the 2010-2011 NFS. 
Wireless Switch center Remained in Sampled County Counties with high movement Counties with moderate movent Counties with low movement Counties with no movement Movement out-of-State Chicago City Boundaries

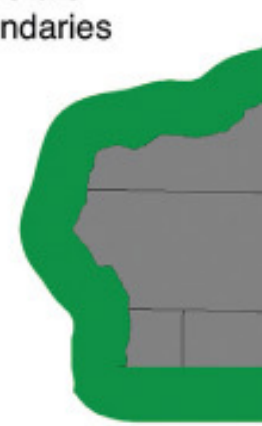

Figure 4 The location of sampled cases and switches around Chicago.

This meant that sampled switches covered a larger area than otherwise desired. A great deal (30.6 percent) of the sample was discarded because the households were within Cook County but outside the City of Chicago.

\section{Conclusion}

Our results support the conclusion that landline sampling has greater geographical accuracy than wireless sampling. We found that smaller geographic units used for sampling resulted in lower geographic accuracy. While there was a substantial amount of variation between local areas in the accuracy of sampled addresses, some of the variation could be explained by the location and density of the switch centers in the geographic area.

When switch locations were examined, several patterns related to geographic accuracy of wireless sampling were observed. When switch locations were distributed evenly throughout the state (such as in Tennessee), the geography accuracy of the original sampling strategy was high as subscribers were more likely to be assigned to a switch close to their residence. When switches were geographically concentrated or unevenly distributed throughout the state (such as in Maine), geographical accuracy decreased (Maine's in area accuracy was 25.3 percent compared to an overall in area accuracy of 40.5 percent). Additionally, in county or sub-county areas where no switches exist (such as New Hampshire and Chicago), geographic accuracy also is decreased. Thus, we conclude that to achieve a relatively high accuracy rate, a targeted area needed a cluster of local switch centers and additional switch centers distributed across adjacent areas. 
Sampling wireless numbers at a sub-state level is possible but poses unique constraints. A geographically targeted survey that includes wireless sample should screen for the respondent's actual location and not rely on sampling information. In the 2010-2011 NFS, when specific small areas were targeted for the wireless survey, it was necessary to draw large oversamples to reach the desired number of interviews in the local area. When our sample target was large (e.g., a state or the entire United States) the geographic accuracy rates were roughly comparable to landline rates. Future work on the specific switch locations may yield some empirical methods for maximizing the accuracy of wireless samples. In addition, other approaches to determining geographic location, such as using billing zip codes (Dutwin 2014), appear promising. Future research should focus on the impact of differential residential mobility on geographic accuracy as respondents move to other locations bringing with them the wireless phones assigned to the original switch location.

\section{Acknowledgement}

The authors wish to thank Xian Tao for her invaluable programming assistance. 


\begin{tabular}{|c|c|c|c|}
\hline Area Name & Definition & $\begin{array}{l}\text { Wireless } \\
\text { completes }\end{array}$ & $\begin{array}{l}\text { Landline } \\
\text { completes }\end{array}$ \\
\hline Arkansas & $\begin{array}{l}\text { AR: Arkansas, Ashley, Bradley, Chicot, Cleveland, Desha, Drew, Jefferson, Lee, } \\
\text { Lincoln, Monroe, Phillips, Prairie, and St. Francis counties }\end{array}$ & 1,070 & 2,193 \\
\hline $\begin{array}{l}\text { AZ- } \\
\text { Maricopa }\end{array}$ & AZ: Maricopa County & 763 & 2,278 \\
\hline CA-Fresno & CA: Fresno County & 661 & 2,355 \\
\hline $\begin{array}{l}\text { CA-Los } \\
\text { Angeles }\end{array}$ & CA: Los Angeles County & 491 & 2,198 \\
\hline Colorado & CO: Denver, Jefferson, Adams, Arapahoe and Douglas counties & 864 & 2,412 \\
\hline Connecticut & CT: New Haven, Hartford, and Middlesex counties & 566 & 2,381 \\
\hline $\begin{array}{l}\text { District of } \\
\text { Columbia }\end{array}$ & Washington DC (NIS Boundaries) & 915 & 2,485 \\
\hline Georgia & GA: Gwinnett and Fulton counties & 1,258 & 2,820 \\
\hline $\begin{array}{l}\text { IL-City of } \\
\text { Chicago }\end{array}$ & IL: Chicago (NIS Boundaries) & 907 & 2,280 \\
\hline $\begin{array}{l}\text { ME- } \\
\text { Cumberland }\end{array}$ & ME: Cumberland County & 1,328 & 2,397 \\
\hline $\begin{array}{l}\text { Ml- } \\
\text { Washtenaw }\end{array}$ & MI: Washtenaw County & 990 & 2,638 \\
\hline Minnesota & MN: Anoka, Carver, Dakota, Hennepin, Ramsey, Scott, and Washington counties & 543 & 2,346 \\
\hline $\begin{array}{l}\text { New } \\
\text { Hampshire }\end{array}$ & NH: Belknap, Coos, and Grafton counties & 2,218 & 2,670 \\
\hline $\begin{array}{l}\text { New } \\
\text { Mexico }\end{array}$ & NM: Sandoval, Santa Fe, Bernalillo, and Valencia counties & 569 & 2,505 \\
\hline New York & New York City: Bronx, Kings, New York County, Queens, Richmond & 419 & 2,211 \\
\hline $\begin{array}{l}\text { PA- } \\
\text { Philadelphia }\end{array}$ & PA: Philadelphia (NIS boundaries) & 720 & 2,222 \\
\hline $\begin{array}{l}\text { TN- } \\
\text { Davidson }\end{array}$ & TN: Davidson County & 1,437 & 2,338 \\
\hline TX-Bexar & TX: Bexar County & 688 & 2,418 \\
\hline $\begin{array}{l}\text { TX-City of } \\
\text { Houston }\end{array}$ & TX: Houston (NIS Boundaries) & 887 & 2,409 \\
\hline WA-King & WA: King County & 762 & 2,315 \\
\hline
\end{tabular}




\section{REFERENCES}

Christian, L., L. Dimock, and S. Keeter. 2009. Accurately Locating Where Wireless Respondents Live Requires More than a Phone Number. Washingtion, DC: Pew Research Center.

Dutwin, D. 2014. “Billing Zip Codes in Cellular Telephone Sampling.” Survey Practice 7 (4).

Dutwin, D., K. Call, D. McAlpine, T. Beebe, R. Rapoport, and N. Buttermore. 2011. "Stratification of Cell Phones: Implications for Research.” In 66th Annual American Association for Public Opinion Research Conference. Phoenix AZ.

Marketing Systems Group. 2012. "Construction of Cellur RDD Sampling Frames Based on Switch Location.” 2012. http://www.m-s-g.com/CMS/ServerGallery/MSGWebNew/Documents/ GENESYS/whitepapers/Cellular-RDD-Frame-Construction.pdf.

Skalland, B., M. Khare, and C. Furlow. 2012. "Geographical Accuracy of Cell Phone Samples and the Effect on Telephone Survey Bias, Variance, and Cost." In American Association for Public Opinion Research 67th Annual Conference. Orlando, FL. 